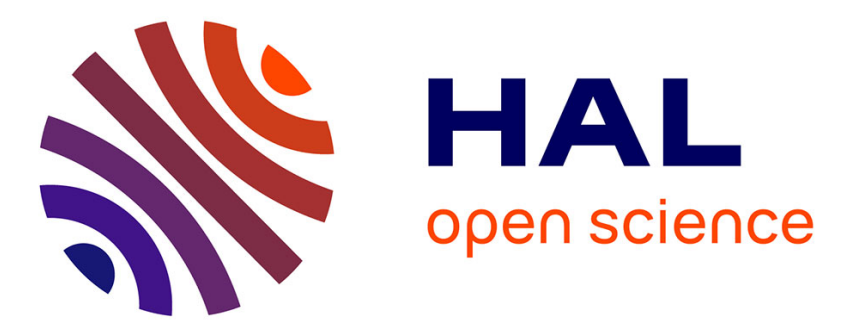

\title{
Characterisation of polyglutamylases in trypanosomatids
} Magali Casanova, Frédérique de Monbrison, Juliette van Dijk, Carsten Janke, Michel Pagès, Patrick Bastien

\section{To cite this version:}

Magali Casanova, Frédérique de Monbrison, Juliette van Dijk, Carsten Janke, Michel Pagès, et al.. Characterisation of polyglutamylases in trypanosomatids. International Journal for Parasitology, 2015, 45 (2-3), pp.121-132. 10.1016/j.ijpara.2014.09.005 . hal-02049686

\section{HAL Id: hal-02049686 \\ https://hal-amu.archives-ouvertes.fr/hal-02049686}

Submitted on 26 Feb 2019

HAL is a multi-disciplinary open access archive for the deposit and dissemination of scientific research documents, whether they are published or not. The documents may come from teaching and research institutions in France or abroad, or from public or private research centers.
L'archive ouverte pluridisciplinaire HAL, est destinée au dépôt et à la diffusion de documents scientifiques de niveau recherche, publiés ou non, émanant des établissements d'enseignement et de recherche français ou étrangers, des laboratoires publics ou privés.

\section{(c)(1)}

Distributed under a Creative Commons Attribution| 4.0 International License 


\title{
Characterisation of polyglutamylases in trypanosomatids
}

\author{
Magali Casanova ${ }^{\mathrm{a}, 1,2}$, Frédérique de Monbrison ${ }^{\mathrm{a}, 1}$, Juliette van Dijk ${ }^{\mathrm{c}}$, Carsten Janke ${ }^{\mathrm{c}, 3}$, Michel Pagès ${ }^{\mathrm{a}}$, \\ Patrick Bastien ${ }^{\mathrm{a}, \mathrm{b}, *}$
}

a Centre National de la Recherche Scientifique (CNRS), 5290-IRD 224-University Montpellier 1, Research Unit “MIVEGEC", Montpellier, France

${ }^{\mathrm{b}} \mathrm{CHU}$ (Hospital University Centre) of Montpellier and University Montpellier 1 (Faculty of Medicine), Laboratoire de Parasitologie-Mycologie, Montpellier, France

'CNRS UMR 5237 - University Montpellier 2 and 1, Research Unit "Centre de Recherche de Biochimie Macromoléculaire", Montpellier, France

\section{A R T I C L E I N F O}

\section{Article history:}

Received 21 July 2014

Received in revised form 16 September

2014

Accepted 17 September 2014

Available online 13 November 2014

\section{Keywords:}

Glutamylation

Polyglutamylases

Microtubules

Leishmania major

Trypanosoma bruce

Tubulin Tyrosine Ligase-Like

\begin{abstract}
A B S T R A C T
Microtubules are subject to post-translational modifications, which are thought to have crucial roles in the function of complex microtubule-based organelles. Among these, polyglutamylation was relatively recently discovered, and was related to centrosome stability, axonemal maintenance and mobility, and neurite outgrowth. In trypanosomatids, parasitic protozoa where microtubules constitute the essential component of the cytoskeleton, the function of polyglutamylated microtubules is unknown. Here, in order to better understand the role of this conserved but highly divergent post-translational modification, we characterised glutamylation and putative polyglutamylases in these parasites. We showed that microtubules are intensely glutamylated in all stages of the cell cycle, including interphase. Moreover, a cell cycle-dependent gradient of glutamylation was observed along the cell anteroposterior axis, which might be related to active growth of the microtubule 'corset' during the cell cycle. We also identified two putative polyglutamylase proteins (among seven analysed here) which appeared to be clearly and directly involved in microtubule polyglutamylation in in vitro activity assays. Paradoxically, in view of the importance of tubulins and of their extensive glutamylation in these organisms, RNA interferencebased knockdown of all these proteins had no effect on cell growth, suggesting either functional redundancy or, more likely, subtle roles such as function modulation or interaction with protein partners.
\end{abstract}

(c) 2014 Australian Society for Parasitology Inc. Published by Elsevier Ltd. All rights reserved.

\section{Introduction}

Microtubules (MTs) are highly conserved dynamic structures made of $\alpha$ - and $\beta$-tubulin heterodimers that are encoded by a family of polymorphic genes and are involved in a variety of essential cell processes such as intracellular transport, mitosis and mobility. In addition to their length and structure variations, MTs can be subject to a series of reversible post-translational modifications (PTMs) (acetylation, phosphorylation, polyglutamylation, polyglycylation, palmitoylation and detyrosination), some of which are very unusual (reviewed in Wloga and Gaertig (2010) and Janke and Bulinski (2011)). Polyglutamylation is a PTM that generates glutamate side-chains of variable length on the gamma-car-

\footnotetext{
* Corresponding author at: CHU (Hospital University Centre) of Montpellier and University Montpellier 1, Laboratoire de Parasitologie-Mycologie, 39 Av. Charles Flahault, 34295 Montpellier cedex 5, France. Tel.: +33 (0)467332350; fax: +33 (0)467332358.

E-mail address: patrick.bastien@univ-montp1.fr (P. Bastien).

1 These authors contributed equally to this work.

2 Present address: Infections Parasitaires, Transmission, Physiopathologie et Thérapeutique, UMR-MD3, Aix-Marseille University, Marseille, France.

${ }^{3}$ Present address: Institut Curie, CNRS UMR 3306, INSERM U 1005, Orsay, France.
}

boxyl group of glutamate residues within the primary sequence of the target protein (reviewed in Janke et al. (2008)). It occurs in a variety of proteins, essentially $\alpha$ - and $\beta$-tubulins (Eddé et al., 1990; Rüdiger et al., 1992), but also the nucleosome assembly proteins NAP1 and NAP2 (Regnard et al., 2000) and other nucleo-cytoplasmic shuttling proteins (van Dijk et al., 2008) that, in higher eukaryotes, are proposed to function in a broad array of physiological activities, through molecular mechanisms as diverse as phosphatase inhibition, chromatin regulation, caspase activation and intracellular transport (Okada et al., 2011; Reilly et al., 2011; Kuryan et al., 2012). The modification is generated by relatively recently discovered polyglutamylating enzymes, members of the Tubulin Tyrosine Ligase-Like (TTLL) family (Janke et al., 2005). TTLLs constitute a large family of proteins that share a homology domain with TTL, another tubulin-modifying enzyme, and whose members can catalyse the ligation of glutamate amino acids to tubulins or other substrates (van Dijk et al., 2008). In mammals, 13 TTLL enzymes exist, among which nine are glutamylases (van Dijk et al., 2007) and three are catalysing a related modification, glycylation (Rogowski et al., 2009; Wloga et al., 2009). Each enzyme displays defined reaction preferences for modifying the $\alpha$ - or $\beta$-tubulin and for generating short or long sidechains 
(van Dijk et al., 2007; Rogowski et al., 2009). Both the polyglutamylation and the polyglycylation reactions consist of two biochemically distinct steps: initiation and elongation, which are often mediated by distinct TTLLs. Initiation is the formation of an isopeptide bond with the gamma-carboxyl group of the glutamate acceptor site, whereas side chain elongation consists of the formation of regular peptide bonds (Redeker et al., 1991; Wolff et al., 1994). It has been proposed that the range of signals generated by the variable length of the added sidechain may allow a fine tuning of the function of MTs and of their interactions with protein partners (Lacroix and Janke, 2011) (reviewed in Janke et al. (2008) and Janke and Kneussel (2010)). Thus, tubulin PTMs, and more specifically polymodifications, are thought to have crucial roles in the assembly, maintenance and function of complex MT-based organelles (reviewed in Janke and Bulinski (2011)).

Polyglutamylation is an ancient phenomenon evolutionarily conserved from protists to mammalian cells; it is present in sperm flagella of mammals, in sea urchins as well as in several protists including Giardia, Tetrahymena, Crithidia and Trypanosoma (Eddé et al., 1990; Seebeck et al., 1990; Bré et al., 1994; Rüdiger et al., 1995; Moulay et al., 1996; Plessmann and Weber, 1997; Schneider et al., 1997; Weber et al., 1997; Westermann et al., 1999). In mammalian cells, tubulin polyglutamylation is related to centrosome stability, axonemal maintenance and mobility in cilia and flagella, and neurite outgrowth (Gagnon et al., 1996; Bobinnec et al., 1998; Million et al., 1999; Westermann and Weber, 2003; Janke et al., 2005; Ikegami et al., 2006; Pathak et al., 2007; Vogel et al., 2010) (reviewed in Janke et al. (2008)). In protists, knowledge of the biological function of polyglutamylated MTs is limited (Wloga et al., 2008; Wloga and Gaertig, 2010) and, in view of the extreme genetic and biological diversity encountered in these organisms (Berriman et al., 2005), probably much more diverse than in mammals.

Trypanosoma and Leishmania are flagellated parasitic protozoa of the Trypanosomatidae family. They have a simple but precisely ordered cytoskeleton, primarily made of stable MTs (Schneider et al., 1997) and, with MTs constituting the most abundant part of their cytoskeleton, they show a reduced dependence on the acto-myosin network (Kohl and Gull, 1998; Berriman et al., 2005). MTs constitute four sub-structures in trypanosomatids: the mitotic spindle, the flagellar axoneme, the basal body of the flagellum and, most importantly, the subpellicular 'corset'. This corset is made exclusively of a dense network of MTs cross-linked to each other and to the plasma membrane, forming a helical pattern along the long axis of the cell (reviewed in Robinson et al. (1995)). It is responsible for the cell shape and plays a major role in events such as positioning of organelles, mitosis and cytokinesis (Sasse and Gull, 1988).

Similar to other organisms, MTs in these parasites are subject to a series of PTMs (detyrosination, acetylation, polyglutamylation) (Wolff et al., 1992; Gull, 1999). Using mass spectrometry analysis, trypanosomatid tubulin has been shown to be extensively glutamylated and non-glutamylated tubulins were reported to be almost absent (Schneider et al., 1997). In contrast, the closely related modification glycylation was not detected in Trypanosoma brucei (Schneider et al., 1997). The discovery that TTLL proteins catalyse tubulin glutamylation (Janke et al., 2005; van Dijk et al., 2007) led us to identify eight TTLL genes in silico in the genome of $T$. brucei. These enzymes belong to five of the diverse subtypes of this protein family (TTLL1, TTLL4, TTLL6, TTLL9 and TTLL12). To understand the role of this evolutionarily conserved but highly divergent PTM (Wloga and Gaertig, 2010) and to better characterise tubulin glutamylation in trypanosomatids, the distribution of polyglutamylated MTs during the cell cycle in Leishmania major and T. brucei was examined using specific antibodies (Abs). The putative TTLL genes of $T$. brucei and $L$. major were then cloned and the subcellular localisation of the gene products determined using GFP-fused recombinant proteins; their enzymatic activities were analysed in vitro and an insight into their putative biological function obtained using RNA interference (RNAi).

\section{Material and methods}

\subsection{Parasites}

Leishmania major 'Friedlin' promastigotes (MHOM/IL/81/Friedlin) were grown as previously described (Dubessay et al., 2004). Procyclic forms of the 29-13 line of $T$. brucei were grown at $27^{\circ} \mathrm{C}$ in SDM 79 (Sigma $^{\circledR}$, MO, USA) supplemented with FCS (10\%), hemin $(7 \mu \mathrm{g} / \mathrm{ml})$, hygromycin $(30 \mu \mathrm{g} / \mathrm{ml})$ and geneticin $(10 \mu \mathrm{g} /$ $\mathrm{ml}$ ) for continuous culture, plus phleomycin $(5 \mu \mathrm{g} / \mathrm{ml})$ for RNAi experiments.

\subsection{Bioinformatics}

The sequences of genes encoding putative TTLL proteins in $L$. major and T. brucei were searched in the MapView database (http://www.genedb.org/genedb/leish/). The corresponding trypanosomatid protein sequences were aligned using Clustal $\mathrm{X}$ and corrected manually as described previously (Wloga et al., 2008).

\subsection{Construction of L. major cell lines expressing GFP fused proteins}

The genes encoding putative TTLLs were PCR-amplified from genomic DNA. The PCR products were cloned into a pGEM-T-Easy vector (Promega ${ }^{\circledR}$, WI, USA) and then inserted into the expression vectors pTH6cGFPn and pTH6nGFPc (Dubessay et al., 2006) which place the GFP fusion at the $\mathrm{N}$-terminus and $\mathrm{C}$-terminus, respectively. The presence of the reading frame of the recombinant proteins was confirmed by sequencing.

Transfection in L. major was performed as described previously (Casanova et al., 2009). Briefly, $5 \times 10^{7}$ cells with $80 \mu \mathrm{g}$ of plasmid DNA were electroporated using a Bio-Rad GENE Pulser II and a Pulse Controller (Bio-Rad, Hercules, USA) at $25 \mu \mathrm{F}$ and $1500 \mathrm{~V}$ with two pulses of $0.5 \mathrm{~ms}$ each and $10 \mathrm{~ms}$ between each pulse. Hygromycin B $\left(\right.$ Sigma $\left.{ }^{\circledR}\right)$ was added at $30 \mu \mathrm{g} / \mathrm{ml}$ for selective pressure.

\subsection{Microscopy and immunofluorescence imaging}

For the intracellular localisation of GFP-fused proteins or for immunofluorescence of whole cells, transfected cells grown to mid-log phase were fixed in $4 \%$ paraformaldehyde (PFA) and airdried on microscope fluorescence slides (Dubessay et al., 2006). For immunofluorescence analysis of cytoskeletons, cells were washed in PBS and deposited on 8-well slides. Cytoskeletons were extracted in $0.25 \%$ Nonidet P40 (NP40), $100 \mathrm{mM}$ piperazine-N, $\mathrm{N}^{\prime}$ bis(2-ethanesulfonic acid) (PIPES), $1 \mathrm{mM} \mathrm{MgCl}$, pH 6.9, for $5 \mathrm{~min}$ at room temperature (Pradel et al., 2006) and then fixed in $4 \%$ PFA for $20 \mathrm{~min}$ for L. major or for $5 \mathrm{~min}$ for T. brucei.

In both immunofluorescence preparations (whole cell or cytoskeleton), fixed cells were incubated with either the GT335 (1:10,000, Adipogen ${ }^{\circledR}$, CA, USA), the PolyE $(1: 10,000$ for $L$. major and $1: 5,000$ for $T$. brucei, made by the authors) or the YL1/2 (1:200, Santa Cruz Biotechnology ${ }^{\circledR}$, CA, USA) Abs for $45 \mathrm{~min}$, followed by 45 min with anti-mouse Alexa 546 or 488 (1:500, Molecular Probes ${ }^{\circledR}$, OR, USA), anti-rabbit Alexa 488 (1:500, Molecular Probes $\left.{ }^{\circledR}\right)$ or anti-rat conjugated with TRITC (1:500; Santa Cruz Biotechnology ${ }^{\circledR}$ ) Abs, respectively.

To study the mitochondrion, cultivated cells were primarily incubated for 10 min at $27{ }^{\circ} \mathrm{C}$ with Mitotracker Red CMXRos (500 $\mathrm{nM}$, Molecular Probes $\left.{ }^{\circledR}\right)$ and washed in culture medium without 
FCS. After a second wash in culture medium with FCS, the cells were fixed as described above.

DNA was visualised by DAPI staining $(0.01 \mu \mathrm{g} / \mathrm{ml})$. Slides were mounted with Mowiol mounting medium (Calbiochem ${ }^{\circledR}, \mathrm{CA}$, USA) and viewed by phase contrast and immunofluorescence microscopy using appropriate filters on a Zeiss ${ }^{\circledR}$ Axioplan 2 microscope with a $100 \times$ objective. Digital images were captured using a Photometrics CoolSnap CDD camera (Roper Scientific ${ }^{\circledR}$, FL, USA) and processed with Metaview Software (Universal Imaging Corporation $^{\circledR}$, PA, USA).

\subsection{Northern blot and western blot}

\subsubsection{Northern blot}

Total RNA from promastigote forms of $L$. major and procyclic forms of $T$. brucei was extracted using a RNeasy extraction kit (Qiagen ${ }^{\circledR}$, Netherlands) and denaturated in a solution of $2.5 \times 3$-(N-morpholino)propanesulfonic acid (MOPS), 9.25\% formaldehyde and $50 \%$ formamide. RNAs were then incubated for $10 \mathrm{~min}$ at $65^{\circ} \mathrm{C}$ and $5-10 \mathrm{~min}$ on ice, before being separated on an agarose gel (1.4\% agarose, $6 \%$ formaldehyde and $1 \times$ MOPS). RNAs were transferred to a nylon membrane (Amersham Hybond-N+, GE Healthcare $^{\circledR}$, UK) and hybridized with a specific DNA probe radio-labelled with $\alpha^{32} \mathrm{P}$-dCTP by random priming. The GPI-anchor transamidase subunit 8 gene (GPI8; LmjF.18.0360 and Tb10.6 1.3060) which is constitutively expressed, was used as a control.

\subsubsection{Western blot}

A total of $2 \times 10^{8} \mathrm{~L}$. major recombinant cells were centrifuged at $600 \mathrm{~g}$ for $10 \mathrm{~min}$ and washed with a protease inhibitor cocktail (complete EDTA-free protease inhibitor cocktail tablets, Roche ${ }^{\circledR}$, Switzerland). Cells were then lysed for $10 \mathrm{~min}$ at $100{ }^{\circ} \mathrm{C}$ in a loading buffer (62.5 mM Tris- $\mathrm{HCl}$ pH 6.8, 2\% SDS, 0.01\% bromophenol blue, 25\% glycerol, 5\% ß-mercaptoethanol). Lysates were separated on a $10 \%$ SDS-PAGE gel and blotted onto a Polyvinylidene difluoride (PVDF) membrane (Bio-Rad ${ }^{\circledR}$ ) saturated with PBS, 5\% skimmed milk and $0.05 \%$ Tween 20 for $1 \mathrm{~h}$. Different primary Abs were used: a mouse anti-GFP $\mathrm{Ab}\left(1: 1,000\right.$, Roche $\left.{ }^{\circledR}\right)$, the mouse anti- $\alpha$-tubulin monoclonal Abs (mAbs) '12G10' $(1: 1,000)$ and GT335 (12G10 was developed by J. Frankel and M. Nelson and obtained from the Developmental Studies Hybridoma Bank, University of Iowa, USA). Immunoprecipitation was revealed with anti-mouse alkaline phosphatase conjugate $\mathrm{Ab}\left(1: 7500\right.$, Promega $\left.{ }^{\circledR}\right)$. The membranes were developed using the nitro-blue tetrazolium/5-bromo-4chloro-3'-indolyphosphate (NBT/BCIP) reaction.

\subsection{In vitro polyglutamylase assays}

Leishmania major expressing recombinant TTLL proteins and $L$. major Friedlin promastigote cells were lysed in $50 \mathrm{mM} 2-(\mathrm{N}$-morpholino)ethanesulfonic acid (MES)/NaOH pH 6.8, 2 mM EGTA, $1 \mathrm{mM} \mathrm{MgCl} 2,0.2 \% \mathrm{NP} 40$ and protease inhibitors (complete EDTAfree protease inhibitor cocktail tablets, Roche ${ }^{\circledR}$ ). Tubulin glutamylase activity was determined as described by Regnard et al. (1998) and Janke et al. (2005). Reaction mixtures (20 $\mu \mathrm{l})$ containing $50 \mathrm{mM}$ Tris- $\mathrm{HCl}$ pH 9, $400 \mu \mathrm{M}$ ATP, $2.4 \mathrm{mM} \mathrm{MgCl} 2,500 \mu \mathrm{M}$ DTT, $4.6 \mu \mathrm{M}$ taxol, $8 \mu \mathrm{M} \mathrm{L}-\left[{ }^{3} \mathrm{H}\right]$-glutamate $(45-55 \mathrm{Ci} / \mathrm{mmol}$, GE Healthcare $\left.^{\circledR}\right), 0.2 \mathrm{mg} / \mathrm{ml}$ of taxol-stabilized MTs and L. major extracts were incubated at $30^{\circ} \mathrm{C}$ for $2 \mathrm{~h}$. The taxol-stabilized MTs were prepared from adult mouse brain MTs or HeLa cells (Regnard et al., 1999). Mice used in this study were maintained in the animal facility of the Centre National de la Recherche Scientifique (CNRS) in Montpellier, France. Procedures involving mice were performed in compliance with national animal welfare laws, guidelines and policies, under the supervision of the regional ethical committee. Quantifications were done by scintillation counting of the $\alpha$ - and $\beta$-tubulin bands after loading of the samples on a 10\% SDS-PAGE and electro-transfer onto nitrocellulose, as previously described (Regnard et al., 1998). Polyglutamylase activity was also determined using ANP32B and NAP1 as substrates, at $0.2 \mathrm{mg} / \mathrm{ml}$.

\subsection{RNAi in T. brucei}

Amplification of parts of $T$. brucei TTLL genes was performed using genomic DNA with the primers listed in Supplementary Table S1. The PCR products including the HindIII (AAGCTT) and SacII (CCGCGG) restriction sites were cloned into a pGEMT-Easy vector (Promega ${ }^{\circledR}$ ) and into a p27T7tiB/GFP vector (trypanoFAN: http://trypanofan.path.cam.ac.uk/trypanofan/main). Linearised plasmid DNA $(10 \mu \mathrm{g})$ was transfected into $3 \times 10^{7} \mathrm{~T}$. brucei procyclic forms using an exponential protocol $(1500 \mathrm{~V}, 25 \mu \mathrm{F})$ on a BioRad $^{\circledR}$ Gene Pulser Xcell ${ }^{\mathrm{TM}}$ electroporation system. Transfectants were grown under drug selective pressure (phleomycin, $5 \mu \mathrm{g} / \mathrm{ml}$ ) for $15-20$ days prior to induction by tetracycline $(1 \mu \mathrm{g} / \mathrm{ml})$ as previously described (Blaineau et al., 2007). Cell type labelling (GT335-positive or -negative) was estimated in the presence and absence of tetracycline as described in Section 2.4. Approximately 800 cells were counted.

\section{Results}

3.1. Distribution of glutamylated and polyglutamylated tubulin in $L$. major and $T$. brucei

While MT polyglutamylation has been reported as extensive in T. brucei from mass spectrometry data (Schneider et al., 1997), no data are available for Leishmania. To visualise glutamylation in trypanosomatid cells, we performed immunofluorescence in $L$. major and $T$. brucei using two Abs directed against polyglutamylated tubulin: GT335 is a mAb that recognises all forms of polyglutamylated tubulin independently of the length of the polyglutamate side chain (Wolff et al., 1992), whereas PolyE is a polyclonal Ab that is specific to tubulin modified by the presence of side chains at least three glutamates long (Rogowski et al., 2009). Contrary to the low level of polyglutamylation in interphase MTs, which is observed in most proliferating mammalian cells (Regnard et al., 1999), the trypanosomatid interphasic cells appeared intensely stained with both antibodies (Fig. 1). Moreover, in L. major cells, GT335 labelling was clearly more intense in $\mathrm{G} 2 / \mathrm{M}$ cells (as defined from the appearance of the nascent flagellum) than in non-mitotic cells (Fig. 1, Supplementary Fig. S1). This shows (and confirms in T. brucei) that MTs are highly polyglutamylated at all stages of the cell cycle. Interestingly, the posterior third of the cell body lacked GT335 labelling in interphasic cells of both species, which was clearly confirmed by the merging of the fluorescence of both antibodies (Fig. 1). However, during the G2/M phase, this relative reduction was no longer observed in $L$. major promastigotes (Fig. 1A, Supplementary Fig. S1), although it persisted in T. brucei procyclic forms (Fig. 1B). This specific immunofluorescence pattern was confirmed using detergent-extracted cytoskeletons in both species (Supplementary Figs. S1 and S2). This experiment also confirmed that polyglutamylation is located in the cortex of MTs and not inside the cell body. Finally, the flagellum was always decorated with the antibodies, although less intensely than the rest of the cell (Supplementary Figs. S1-S3). In contrast with mammalian cells (Bobinnec et al., 1998), the centrioles of the basal body, as well as the mitotic spindle, were not distinctly labelled by the antibodies.

The differential distribution of GT335 labelling being reminiscent of the distribution of (de)tyrosinated $\alpha$-tubulin (Sasse and Gull, 1988), we wanted to see if there was a correlation between 
A
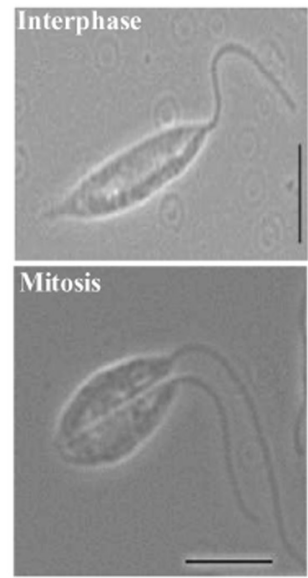

B
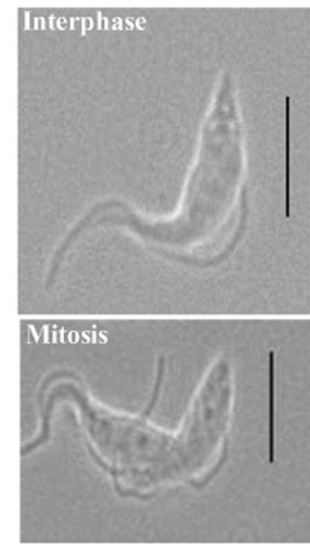

Phase contrast
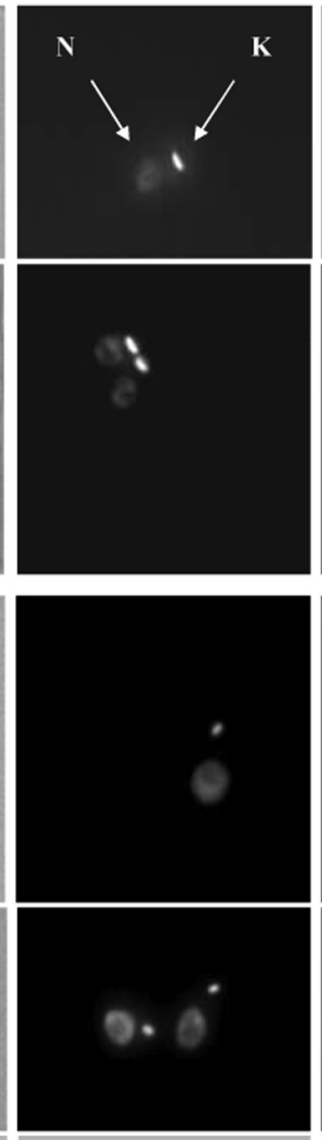

DAPI
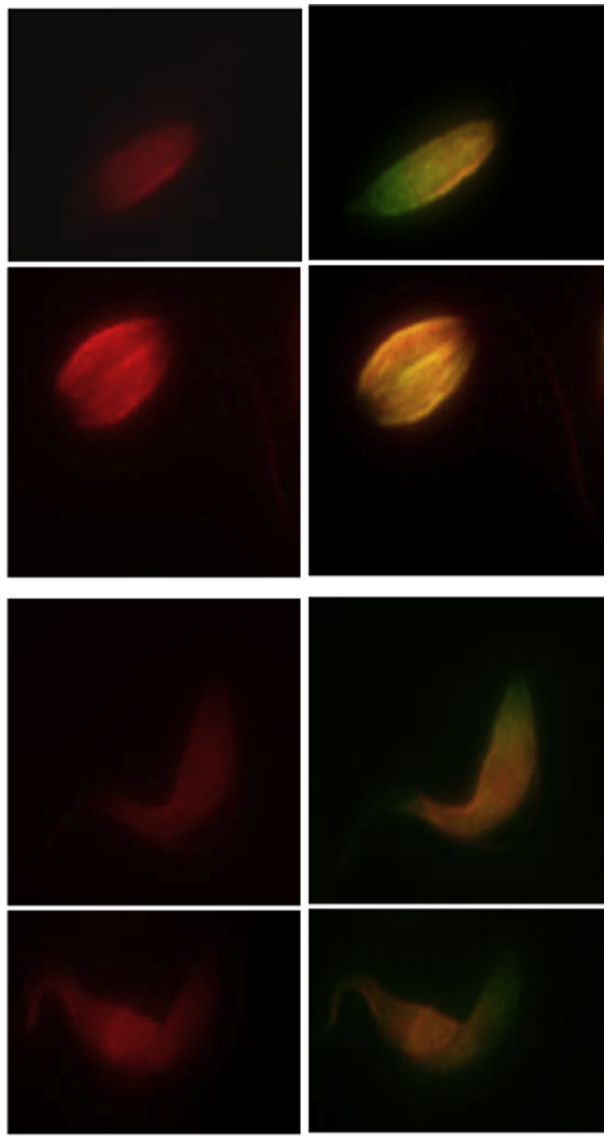

GT335

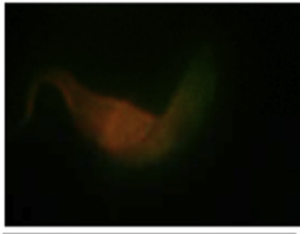

GT335 (red)/PolyE (green)

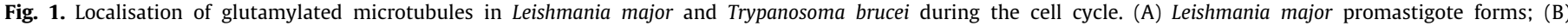

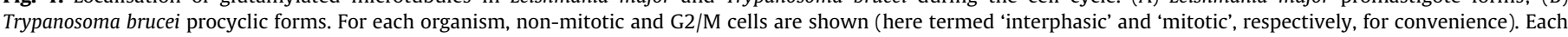

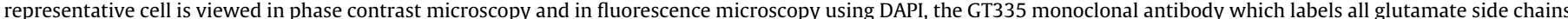

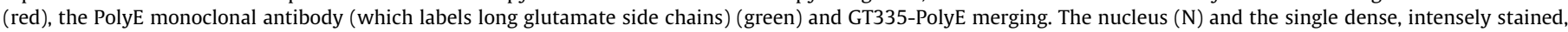
mitochondrial DNA (K for kinetoplast) are stained with DAPI. Bar $=5 \mu \mathrm{m}$.

the distribution of glutamylated and tyrosinated MTs. As expected (Sherwin et al., 1987), the tyrosination-specific antibody YL1/2 clearly labelled the basal body in both species (Figs. 2 and 3). It also intensely decorated the cleavage furrow in L. major mitotic cells (Fig. 3). Moreover, also as previously described (Sasse and Gull, 1988), YL1/2 labelling was distributed over the whole cell body, with an increase in the posterior third of the cell in $T$. brucei (Fig. 2), i.e. the cell region where GT335 labelling was partially deficient. This observation was also made in non-mitotic cells of L. major (Fig. 3).

\subsection{Identification of the genes encoding putative TTLL proteins in $L$. major and T. brucei}

Using bioinformatics, we identified nine and 10 genes encoding proteins with a TTL domain in the L. major and T. brucei genomes, respectively. Two genes in $L$. major and one in $T$. brucei code for proteins with a high sequence homology to TTL (Table 1, Supplementary Table S1). Following phylogenetic studies described in Janke et al. (2005), the trypanosomatid TTLL proteins are classified into five families: TTLL1, TTLL4, TTLL6, TTLL9 and TTLL12. The analysis of the predicted domains of most of these putative TTLLs identified a core TTL domain with an ATP binding site, a domain which is the common hallmark of TTLL proteins, and an extended domain which is characteristic of the polyglutamylase activity (Fig. 4). Two proteins, classified as TTLL12 and present only in $T$. brucei, did not exhibit an extended domain and their homologue in mammals has previously been shown to not act as a tubulin glutamylating enzyme (van Dijk et al., 2007). Thus the seven remaining putative polyglutamylase proteins were examined in the two species (Table 1).

mRNA levels of the putative polyglutamylase genes were evaluated by northern blot analysis of the promastigote forms of $L$. major and procyclic forms of T. brucei. All of the genes were clearly transcribed compared with GPI8, a constitutively expressed gene (Supplementary Fig. S4). Using this crude measurement, ttll4a seems to show high expression levels in both species, and ttll6b seems to be expressed at very high levels in L. major, while ttll6a and ttll9 appeared to be expressed at low levels in T. brucei. These results are actually corroborated by the comprehensive RNA-seq study in L. major by Rastrojo et al. (2013), which showed RNA levels of $t t l 4 a$ and $t t l 6 b$ threefold higher than those of most the other genes.

\subsection{Subcellular distribution of GFP-fused putative polyglutamylases}

We constructed $L$. major recombinant strains expressing GFPfused TTLL proteins. The expression of the GFP-fused proteins in recombinant cells was verified by western blot using an anti-GFP antibody (Supplementary Fig. S5) and their subcellular localisation was analysed using fluorescence microscopy. In order to rule out any bias due to the tag insertion, the GFP tags were introduced 

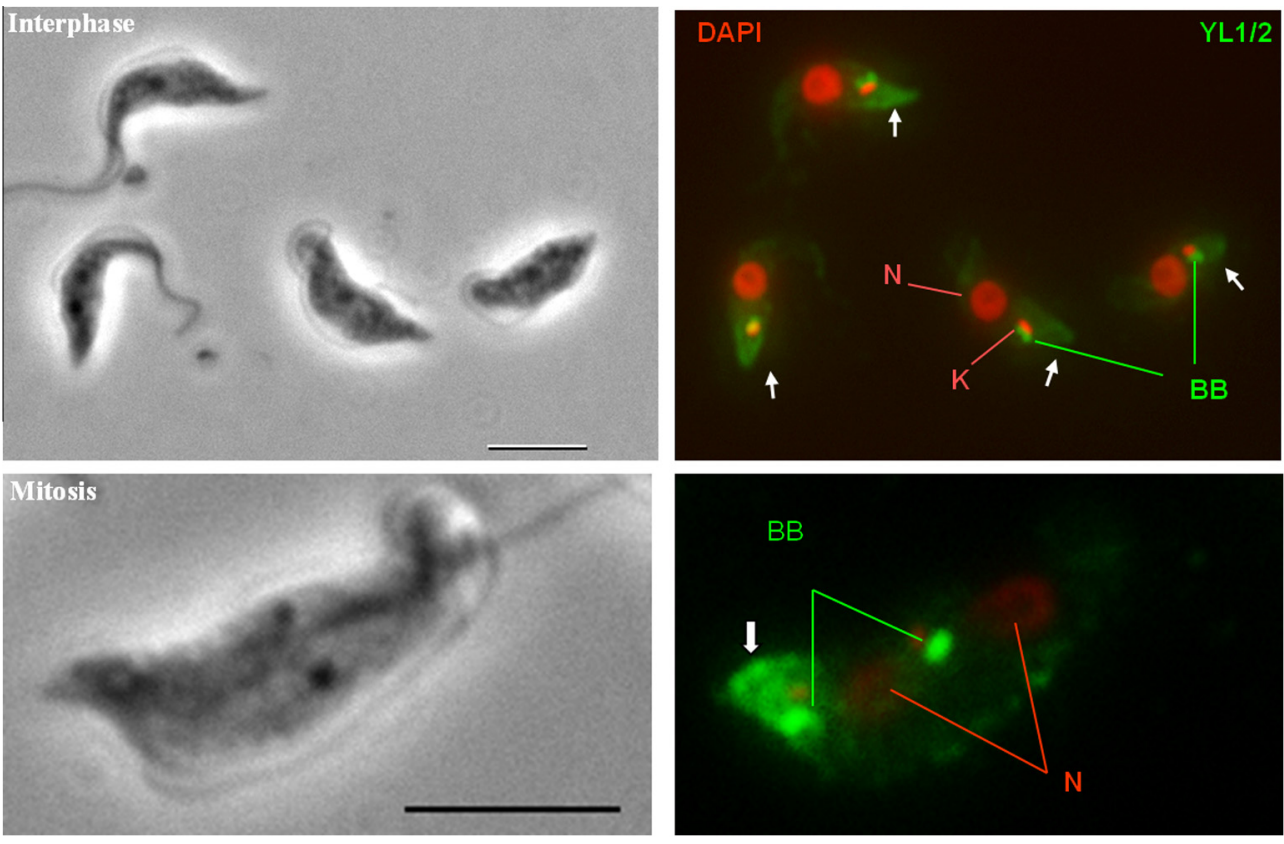

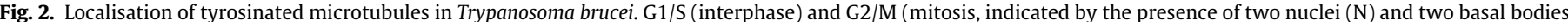

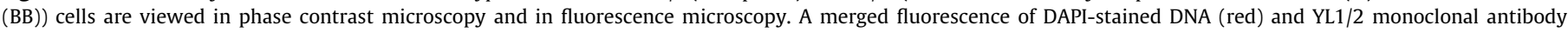

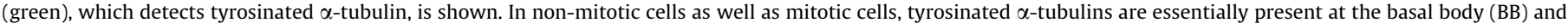
the posterior third of the cell (white arrows). $\mathrm{K}$, kinetoplast. Bar $=5 \mu \mathrm{m}$.
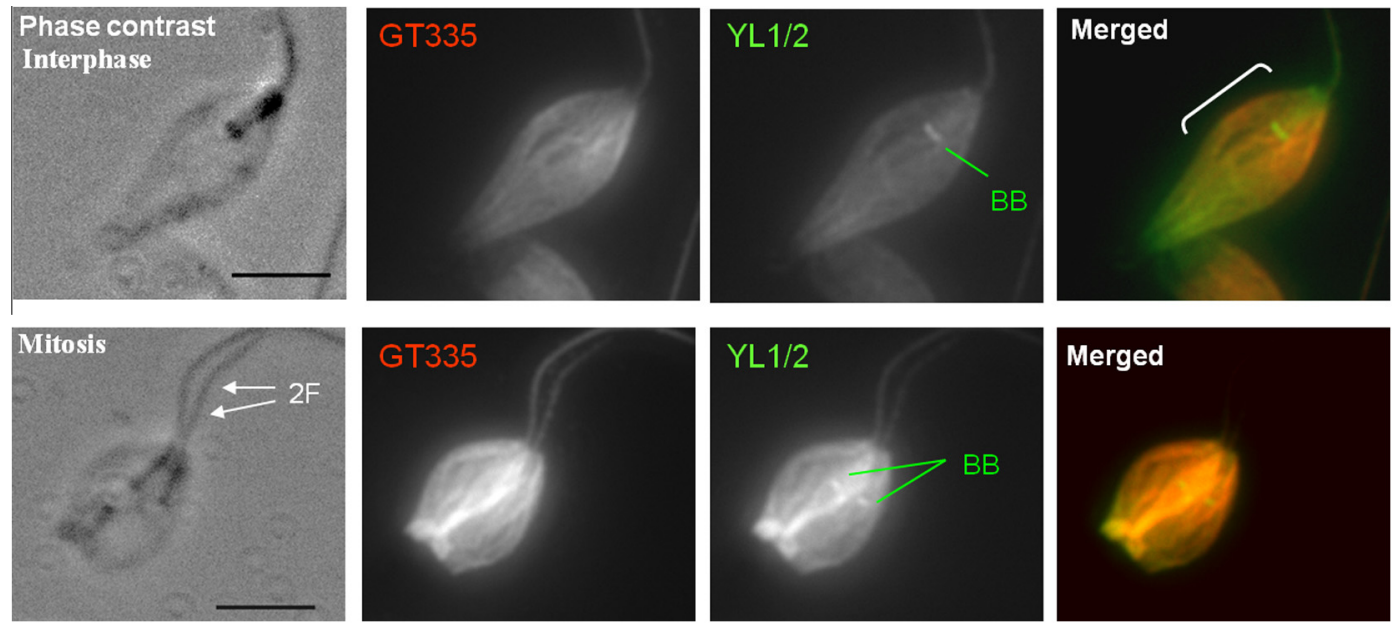

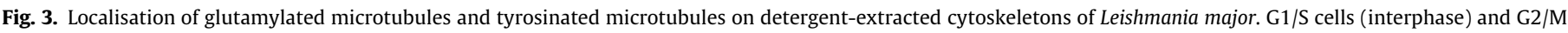

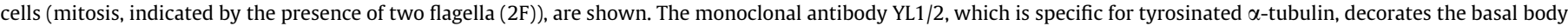

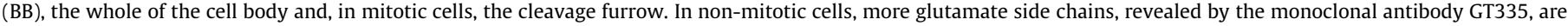
present at the anterior part of the cell (brackets). By contrast, mitotic cells are intensely labelled by both antibodies. Bar $=5 \mu \mathrm{m}$.

at the $\mathrm{N}$ - and at the $\mathrm{C}$-terminal ends in independent experiments: both constructs (LmTTLL-GFPn/LmTTLL-GFPc) gave identical results for all genes except for TTLL4B (see below), indicating that the GFP tag did not modify the localisation of these proteins.

Four of the recombinant TTLL proteins (LmTTLL1, LmTTLL6A and $6 \mathrm{~B}$, and LmTTLL9) showed a diffuse distribution in the cell body but were excluded from the nucleus (Fig. 5). In addition, LmTTLL6B-GFP exhibited an intensely fluorescent dot at the very posterior end of the cell. LmTTLL4A-GFP showed a diffuse localisation and was particularly concentrated in the nucleus (Fig. 6). Surprisingly, LmTTLL4B-GFPc was located exclusively in the mitochondrion, as confirmed by co-localisation with the mitochondrial marker Mitotracker ${ }^{\mathrm{TM}}$ (Fig. 6). Accordingly, an in silico analysis of the sequence of LmTTLL4B revealed a mitochondrial addressing signal at the $\mathrm{N}$-terminus of the protein, which also explained why the N-terminally tagged protein did not localise to the mitochondrion. Finally, LmTTLL4C-GFP was exclusively seen in the nucleus, with a pronounced accumulation at the mitotic spindle in G2/M cells, and at the midbody in anaphase (Fig. 6).

3.4. In vitro polyglutamylation activity and substrate specificity of the L. major recombinant TTLL proteins

In vitro assays with taxol-stabilised MTs (Regnard et al., 1998; van Dijk et al., 2007) were performed in order to test the tubulin polyglutamylase activity of recombinant TTLL proteins from GFPTTLL expressing $L$. major cells. To determine whether these were involved in the initiation or the elongation of glutamate side 
Table 1

Identification of the genes encoding putative Tubulin Tyrosine Ligase and Tubulin Tyrosine Ligase-Like proteins in Leishmania major (Lm) and Trypanosoma brucei (Tb).

\begin{tabular}{|c|c|c|c|}
\hline \multirow[t]{2}{*}{ TTLL code } & \multicolumn{2}{|c|}{ Reference number of gene sequence ${ }^{a}$} & \multirow[t]{2}{*}{ Annotation in GeneDB $(\mathrm{Lm}, \mathrm{Tb})^{\text {a }}$} \\
\hline & L. major & T. brucei & \\
\hline TTLA & LmjF.27.2490 & Tb927.2.5250 & Tubulin Tyrosine Ligase-Like protein \\
\hline TTLB & LmjF.32.2930 & - & Tubulin Tyrosine Ligase-Like protein \\
\hline TTLL1 & LmjF.16.0380 & Tb927.5.3860 & Tubulin Tyrosine Ligase, putative \\
\hline TTLL4A & LmjF.35.4930 & Tb927.9.9580 & Tubulin tyrosine ligase, putative \\
\hline TTLL4B & LmjF.30.2280 & Tb927.6.3570 & Tubulin Tyrosine Ligase-Like protein \\
\hline TTLL4C & LmjF.20.0790 & Tb927.1.1550 & Tubulin tyrosine ligase, putative \\
\hline TTLL6A & LmjF.29.0260 & Tb927.3.5380 & Hypothetical protein, conserved \\
\hline TTLL6B & LmjF.11.0400 & Tb927.11.6810 & Tubulin Tyrosine Ligase-Like protein \\
\hline TTLL9 & LmjF.18.0370 & Tb927.10.13870 & Tubulin Tyrosine Ligase putative \\
\hline TTLL12A & - & Tb927.11.2390 & Hypothetical protein, conserved \\
\hline TTLL12B & - & Tb927.11.2420 & Hypothetical protein, conserved \\
\hline
\end{tabular}

LmjF, Leishmania major Friedlin strain; Tb927, Trypanosoma brucei brucei 927 strain.

a http://www.genedb.org.

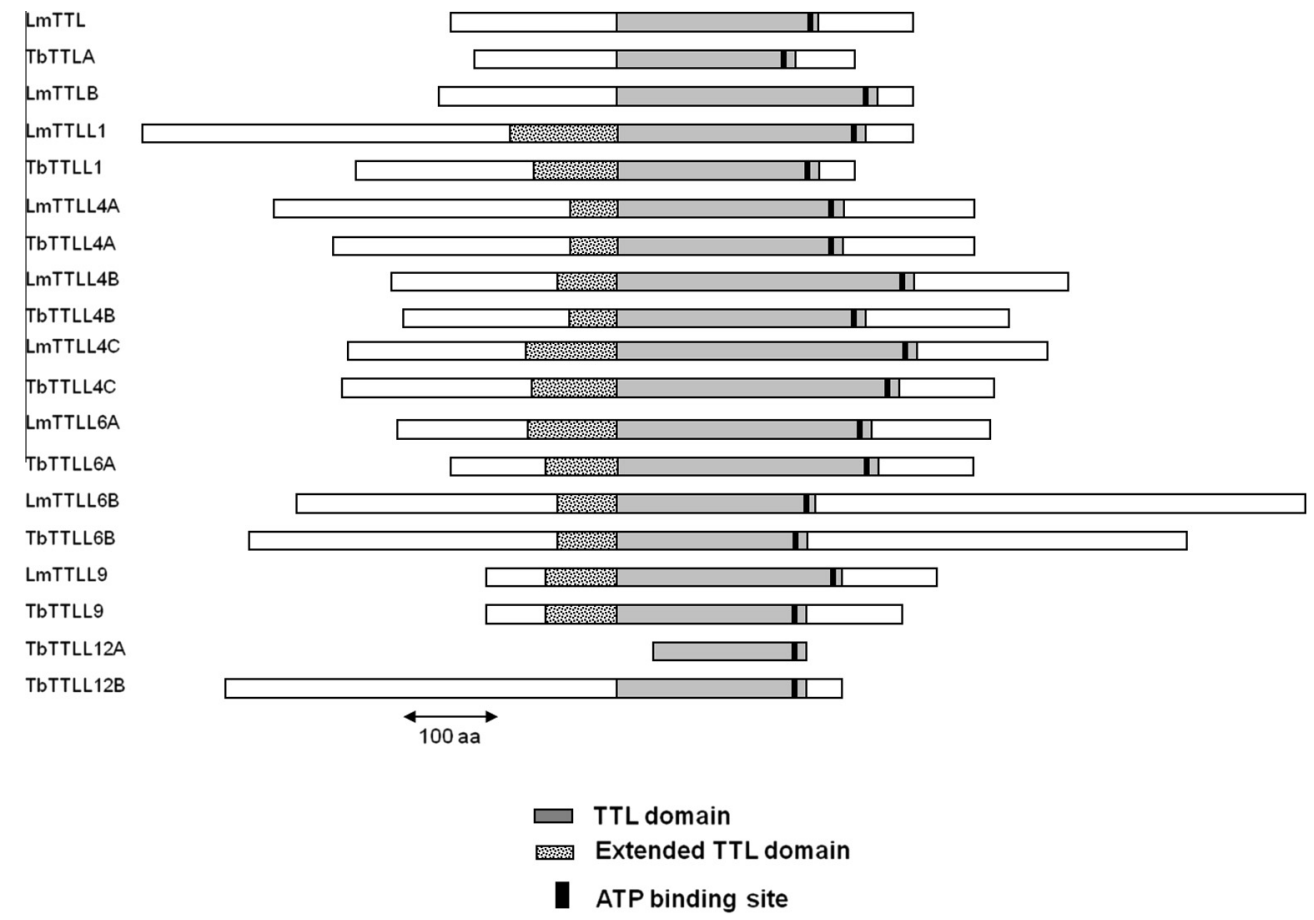

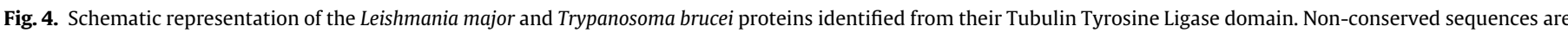
drawn in white. The respective positions of the various domains are detailed in Supplementary Table S1. aa, amino acids.

chains, we used two kinds of substrates: highly polyglutamylated MTs from brain tissue and almost unmodified MTs from HeLa cells. While both initiating and elongating enzymes can act on the brain MTs by either generating new side chains or increasing the length of the pre-existing side chains, HeLa MTs are solely modified by enzymes able to initiate the formation of side chains (van Dijk et al., 2007).

LmTTLL4A and LmTTLL6B were found to be active on both MT substrates. Their ability to modify HeLa tubulin demonstrates that these enzymes possess a chain-initiating polyglutamylase activity (Fig. 7A). LmTTLL6B preferentially modifies $\beta$-tubulin subunits, and can therefore be classified as a $\beta$-tubulin chain-initiating polyglutamylase.

In order to study the glutamylase activity towards substrates other than the tubulins, we performed the same in vitro assays for LmTTLL4A, LmTTLL4B, LmTTLL4C, LmTTLL6A and LmTTLL6B using recombinant NAP1 and ANP32B, two non-tubulin substrates strongly modified by some of the mammalian TTLLs (Regnard et al., 2000; van Dijk et al., 2008). Again, LmTTLL4A and LmTTLL6B proved to be the only clearly active enzymes: LmTTLL6B presented a high glutamylase activity on NAP1 and ANP32B, whereas LmTTLL4A presented activity on ANP32B only (Fig. 7B and C). Very slight activity was seen on NAP1 only for LmTTLL4C and LmTTLL6A, while LmTTLL4B exhibited no significant glutamylase activity on either of the substrates (Fig. 7B and C).

\subsection{Functional analysis of trypanosomatid TTLL proteins by RNAi in $T$.} brucei

Studying loss-of-function phenotypes by gene knockout is usually cumbersome in Leishmania due to a 'mosaic aneuploidy' that leads to frequent generation of extra chromosomal copies in this organism (Dubessay et al., 2002; Sterkers et al., 2011). Moreover, RNAi is not functional in $L$. major due to the absence of proteins of the interference pathway (Robinson and Beverley, 2003), but can be used in T. brucei (Shi et al., 2000). We therefore independently transfected RNAi vectors targeting all seven TTLL genes into T. brucei procyclic forms, and subsequently studied the RNAi- 


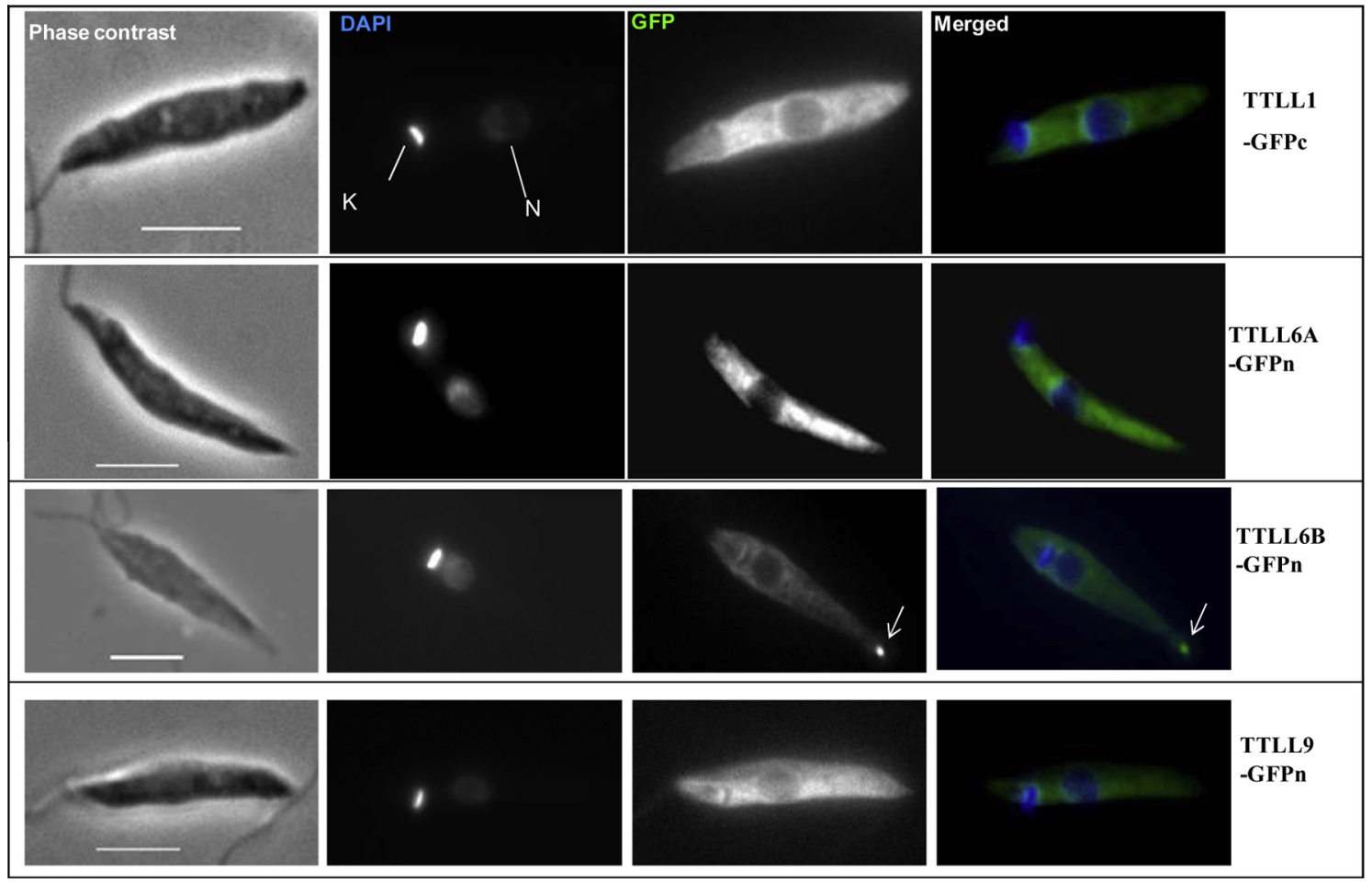

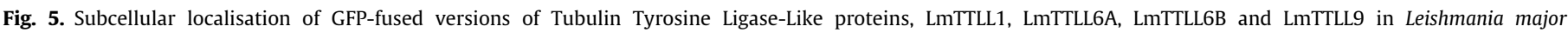

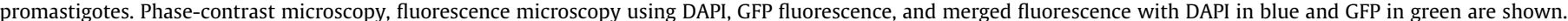

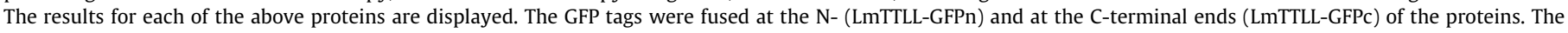

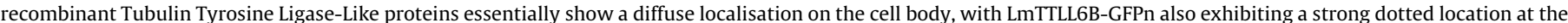

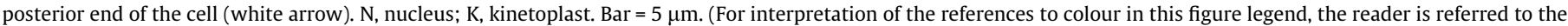
web version of this article.)

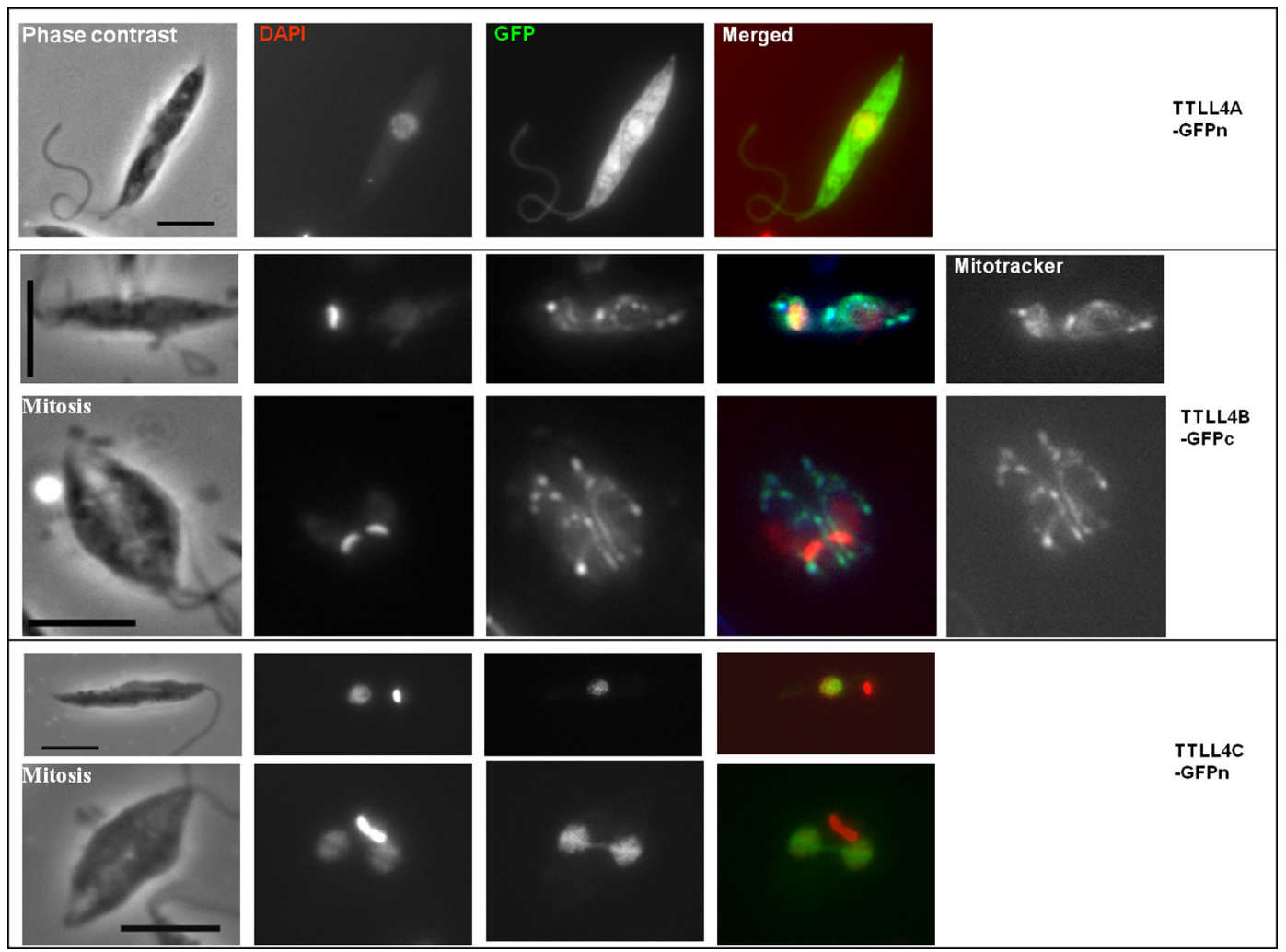

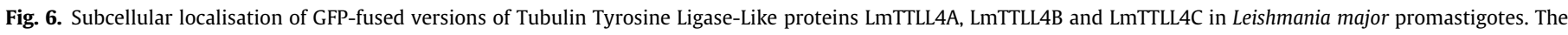

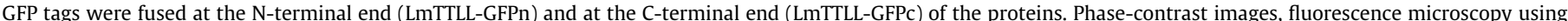

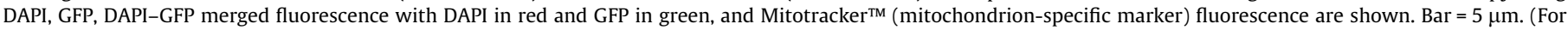
interpretation of the references to colour in this figure legend, the reader is referred to the web version of this article.) 


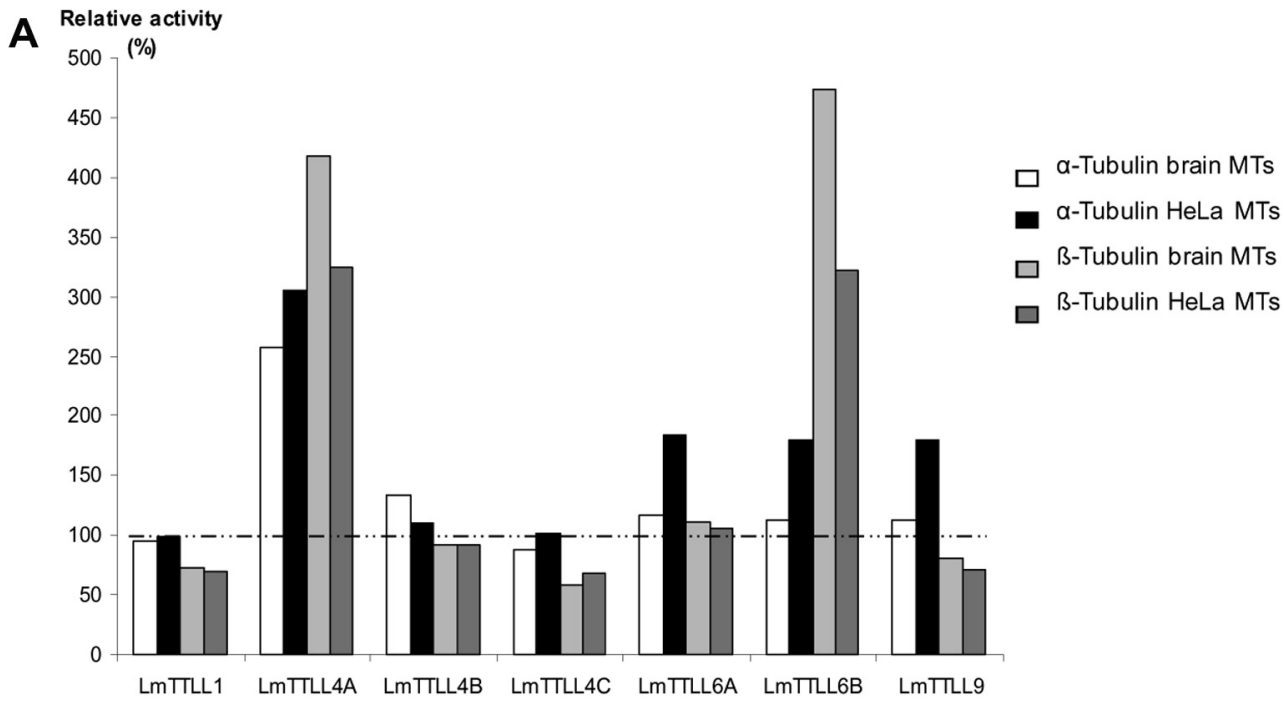

B

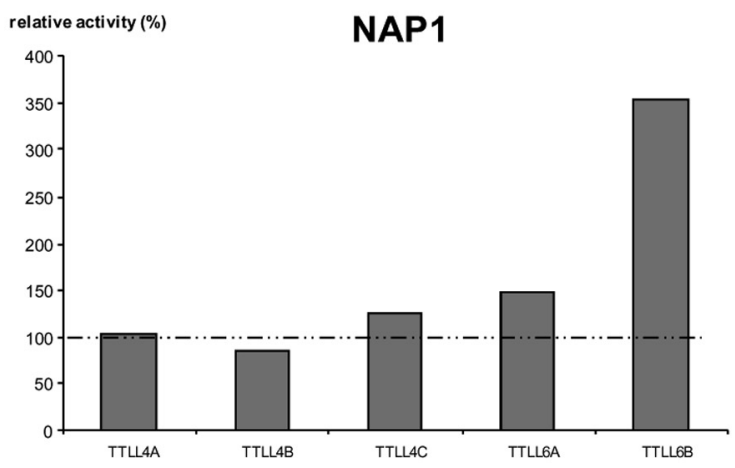

C

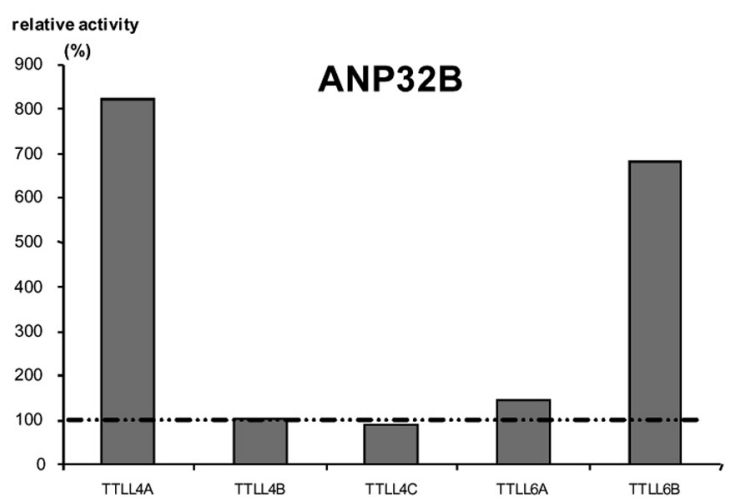

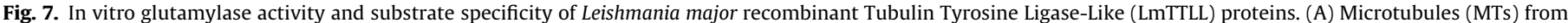

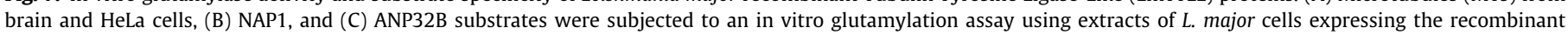

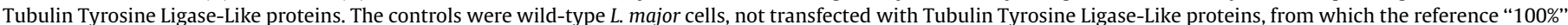

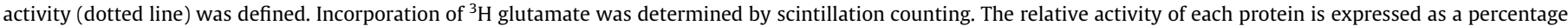
over the total activity in the control reaction.

induced phenotypes such as cell growth, cytokinesis and glutamylated tubulin distribution.

RNAi against TbTTLL4B, the TTLL protein identified as mitochondrial in L. major and with a similar mitochondria-addressing signal in T. brucei, induced a significant cell growth defect 5 days after induction, which was accompanied by a blockage of cytokinesis. The cytokinesis phenotype was revealed by a significant increase in the numbers of multinucleated ( $\geqslant 3$ nuclei) and anucleated cells termed 'zoids' (Robinson et al., 1995), contrasting with a low number of kinetoplasts (Fig. 8A and B).

In contrast, RNAi targeting the remaining TbTTLL genes had no effect on growth, although all of those efficiently depleted their respective targets as shown by northern blots (Supplementary Fig. S6). With respect to cell morphology, a moderate but statistically significant increase in multinucleated cells and in zoids was noted in TbTTLL4A- and TbTTLL6B-RNAi cell lines, respectively, as well as a reduction in mononucleated cells (Fig. 8C). Since both proteins act as initiating polyglutamylases in vitro, we hypothesised that they could have redundant functions in vivo. A double RNAi for TbTTLL4A and TbTTLL6B was performed; induced cells exhibited no growth defect (Supplementary Fig. S7), but the cell cycle disruption appeared even more significant (Fig. 8C, Supplementary Table S2), suggesting a possible synergy between both proteins.
We then studied the effect of RNAi on glutamylation of MTs in TbTTLL4A-RNAi, TbTTLL6B-RNAi and the corresponding double RNAi cell lines, using the GT335 and PolyE Abs (Fig. 9). Cells labelled by GT335 were counted and the mean percentage of GT335-stained cells in the population determined in all lines at day 5 after tetracycline induction. After TbTTLL4A RNAi induction, the fluorescence of PolyE observed by microscopy appeared not to be affected by RNAi, suggesting a compensating elongation of the side chains by other enzymes. By contrast, the proportion of GT335-labelled cells was reduced from 93.7\% to 63.5\% (noninduced and tetracycline-induced populations, respectively). No difference was observed after the TbTTLL6B-RNAi. However, following the double TbTTLL4A + TbTTLL6B RNAi (Fig. 9), the reduction in the proportion of GT335-labelled cells was much greater, from $89.2 \%$ to $47.6 \%$ in non-induced and tetracycline-induced cells, respectively. The reduction in GT335-tubulin staining following double RNAi could also be seen using western blots (Fig. 9).

\section{Discussion}

In trypanosomatids, MTs constitute a particularly essential component of the cytoskeleton, as other classical cytoskeletal components such as actin have a minimal function. As major determinants of flagellar length dynamics (Blaineau et al., 2007) and 


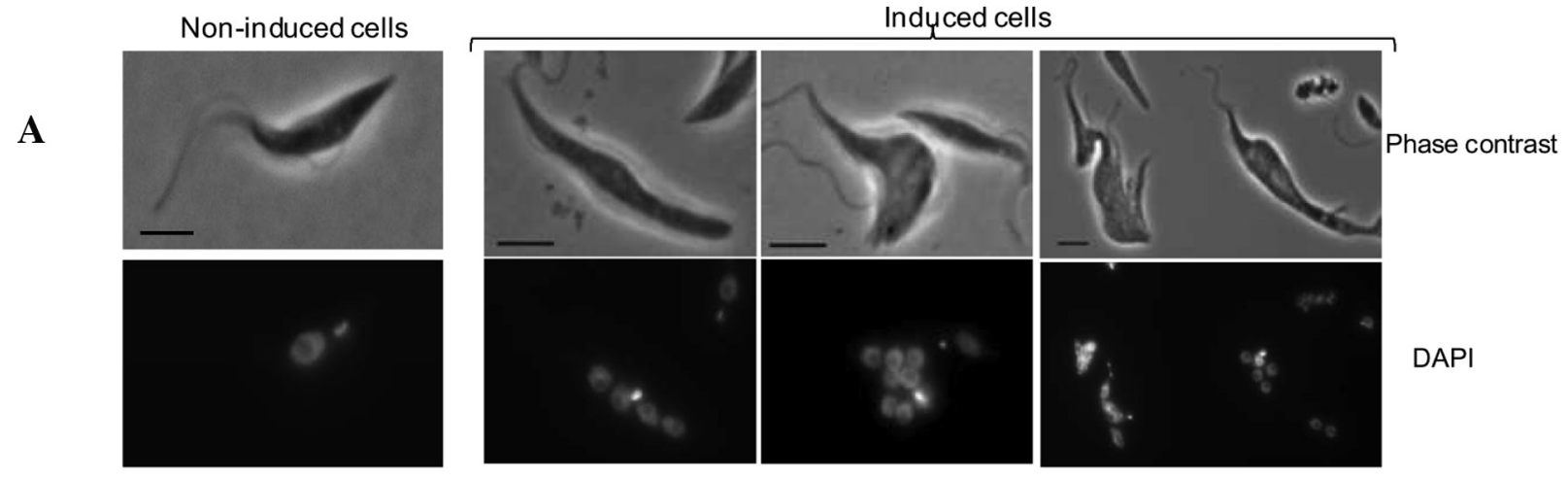

B TbTTLLAB
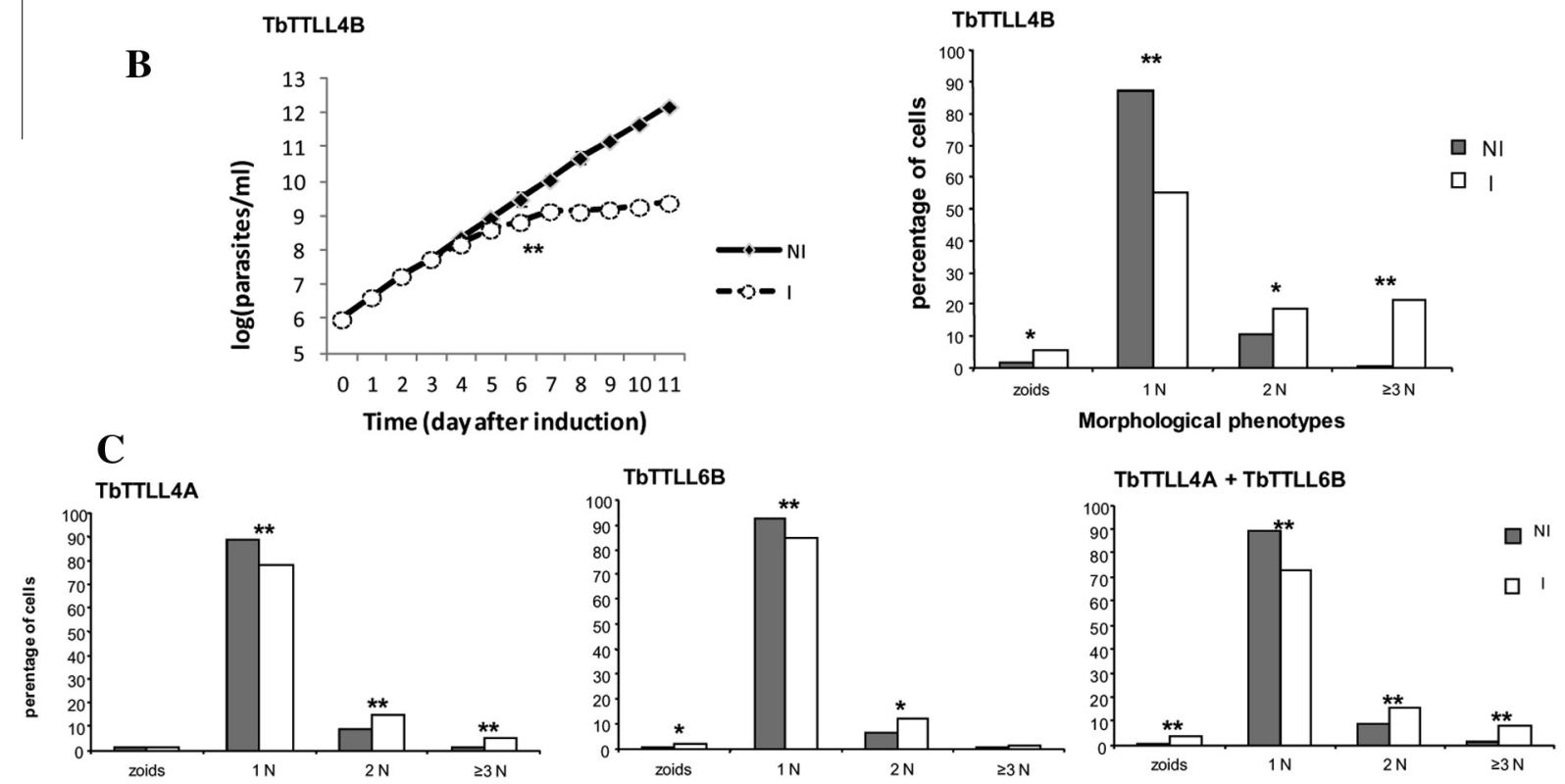

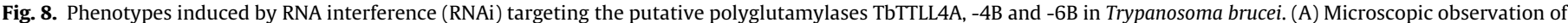

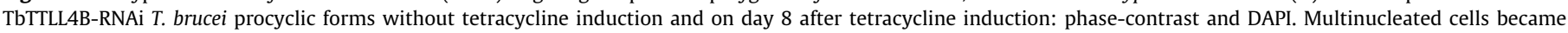

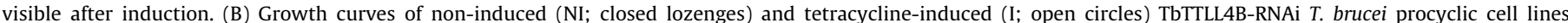

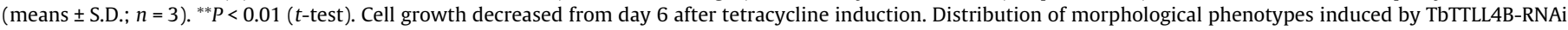

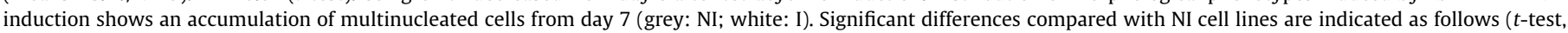

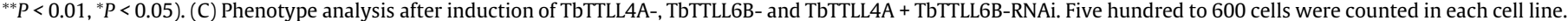

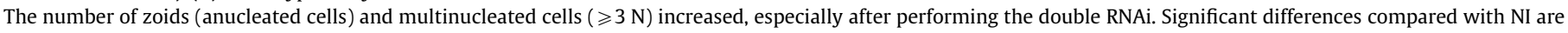
indicated as follows ( $t$-test, ${ }^{* *} P<0.01 ;{ }^{*} P<0.05$ ).

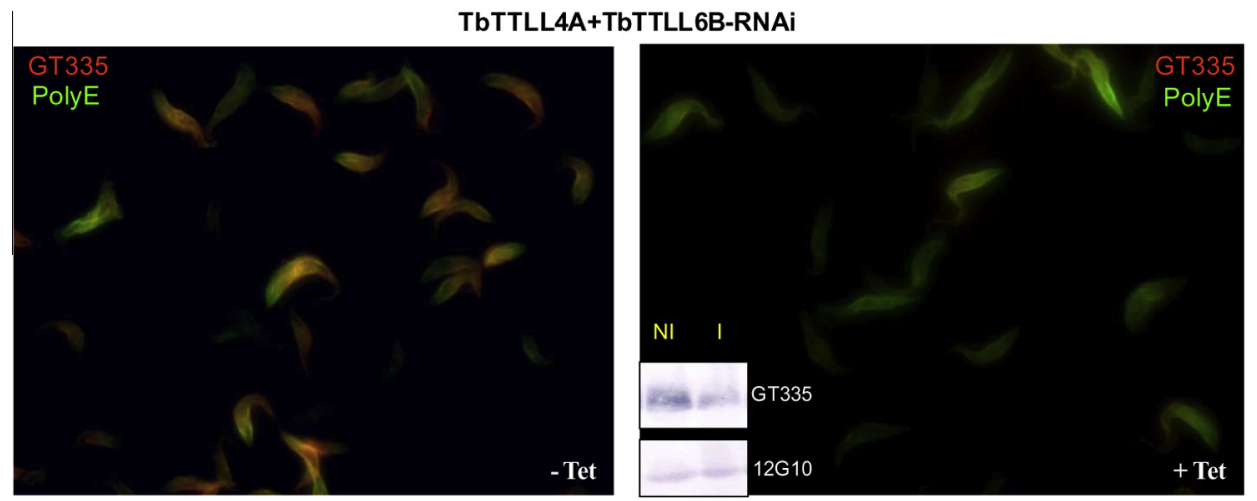

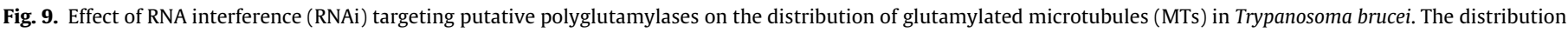

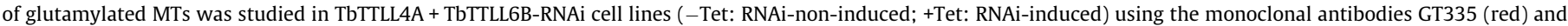

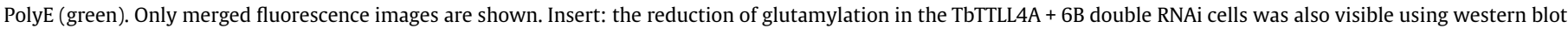

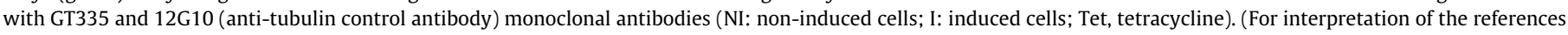
to colour in this figure legend, the reader is referred to the web version of this article.) 
morphogenesis (Gull, 1999), they are essential for parasites that display transformations in cell shape and organelle positioning during their life cycle (Robinson et al., 1995). Finally, and classically, they participate in intracellular transport, mitosis and cell division. Due to the particular structure of MTs, assembled from heterodimers of $\alpha$ - and $\beta$-tubulin, PTMs along these structures are likely to encode novel information for the cell, both linked to the nature, length and spacing patterns of these modifications. Indeed, the modified tubulin subunits are non-uniformly distributed along MTs and, as stated previously, "analogous to the model of the 'histone code', diverse PTMs are proposed to form a biochemical 'tubulin code' that can be 'read' by factors that interact with microtubules" (Verhey and Gaertig, 2007). Polyglutamylation indeed affects processes such as the interaction of MTs with kinesins, MT-associated proteins (MAPs) or MT-severing factors through a modulation of affinity depending on the polyglutamate chain length (Boucher et al., 1994; Wolff et al., 1994; Larcher et al., 1996; Bonnet et al., 2001; Lacroix et al., 2010). Here, we sought to explore the extension and relevance of this process in trypanosomatids. This report presents an updated insight into MT glutamylation and is, to our knowledge, the first published study of putative glutamylases in these parasites.

Contrasting with what is known in mammalian proliferative cells, the study of the distribution of polyglutamylation confirmed that interphasic cells are highly glutamylated in trypanosomatids. As glutamylation often accumulates in stable MTs, this is consistent with the extreme stability of the cytoskeleton of trypanosomatids (Sasse and Gull, 1988), in contrast to the highly dynamic MTs in interphasic mammalian cells. Furthermore, we observed a distinctive labelling of the posterior third of the cells, which was decorated by the Ab PolyE but not by GT335. The simplest explanation for this finding would be that fewer glutamylated tubulins are present at the posterior end of the cell but they carry, on average, longer side chains. An alternative hypothesis might be that GT335 is not as insensitive to the side chain organisation as claimed. In any case, this differential distribution of polyglutamate side chains is strikingly reminiscent of the distribution of detyrosinated $\alpha$ tubulin. Indeed, stable MTs also often accumulate detyrosinated tubulins, whereas tyrosinated $\alpha$-tubulin is a marker for newly assembled MTs; these were shown, in T. brucei, to be more present and to elongate at this same posterior end, termed 'dynamic', during the G1/S phase (Robinson et al., 1995; Sherwin et al., 1987; Sherwin and Gull, 1989; our data). The differential staining between GT335 and YL1/2, which recognises tyrosinated tubulins, is in agreement with the idea that MTs are more dynamic in the posterior third of the cell. Thus, our data show a differential and dynamic pattern of MT glutamylation in the posterior end of the cell, which we hypothesise is related to active growth of the MT corset during the cell cycle.

The differential pattern of glutamylation is modified at the G2/ M stage in L. major since, at this stage, we constantly observed intensification, as well as extension, of both GT335 and YL1/2 labelling over the whole cell body (Figs. 1 and 3 ). Both were particularly intense on the cytokinesis furrow during cytokinesis. Surprisingly, this was not observed in $T$. brucei, suggesting differences in the use of PTMs of MTs between both trypanosomatids, which might be related to the major differences (e.g. the symmetric/asymmetric nature) in cell division between both organisms (Wheeler et al., 2011).

Among the seven TTLL proteins studied here two, LmTLLL4A and LmTTLL6B, appear clearly and directly involved in MT glutamylation in vitro. This function is further supported by the marked reduction in GT335 labelling in vivo when the levels of both proteins were jointly reduced. It can be stressed that both enzymes are expressed at high levels in vivo in L. major and T. brucei (Supplementary Fig. S4). In vitro glutamylation assays further allowed classification of LmTTLL6B as a $\beta$-tubulin initiating glutamylase. It is noteworthy that the inhibition of TbTLLL4A and/or TbTTLL6B had little effect on growth curves; nevertheless, zoids and multinucleated cells increased, particularly after double RNAi, thereby suggesting that polyglutamylation might (directly or indirectly) play a role in mitosis/cytokinesis. Finally, when we tested the in vitro polyglutamylation of two other well-known substrates of polyglutamylases, NAP1 and ANP32B, only LmTTLL4A and LmTTLL6B demonstrated clear activity on these nuclear substrates, of which two orthologues (Lmjf.31.1750/Tb927.9.5730 and Lmjf.19.0440/Tb927.10.15180) are annotated in the genome sequence.

Different hypotheses could explain the failure to observe a clear in vitro glutamylation activity for the remaining recombinant LmTTLL proteins: expression at low levels relative to the endogenous proteins, inhibition of the protein expression in the particular life cycle stage (promastigote) used for this study, inadequate substrates used to test for these proteins, or the lack of an activation step or cofactors for enzyme activity (Janke et al., 2005; van Dijk et al., 2007). In particular, TTLL1 in higher eukaryotes is known to be active only as part of a multiprotein complex (Janke et al., 2005). Therefore, the in vitro polyglutamylation assay used here does not allow us to rule out enzymatic activity of the remaining TTLL proteins.

Two putative polyglutamylases, LmTTLL4A and LmTTLL4C, were partially or exclusively (respectively) located at the nucleus. As seen above, LmTTLL4A was strongly active on ANP32B and MTs. LmTTLL4C, which is exclusively nuclear, showed weak activity on NAP1, whereas mammalian TTLL4 has very strong activity on NAP1 (van Dijk et al., 2007). As a consequence, the correct substrate for LmTTLL4C might be a nuclear protein that has not been tested here. Since inhibition of the expression of TTLL4C did not cause any notable growth reduction, we hypothesise that this action might take place at more subtle levels of regulation or differentiation, and/or that redundancy between TTLLs might occur.

Finally, LmTTLL4B exhibited a highly peculiar localisation, being exclusively present in the single mitochondrion of $L$. major. This putative polyglutamylase showed no activity on either MTs or NAP1/ANP32B. It is likely that the substrates of this enzyme, which were not searched for in this study, are mitochondrial proteins. Furthermore, the inhibition of this enzyme induces growth arrest and, specifically, a blockage of cytokinesis, which is induced by its expression inhibition. In trypanosomatids, cytokinesis is directly dependent upon smooth progress of the part of the cell cycle associated with the kinetoplast, the single and complex mitochondrial DNA (Robinson et al., 1995). The identification of the substrate(s) of this enzyme should assist in clarifying the complex mechanisms regulating this original step in the cell cycle (Hammarton, 2007).

In conclusion, PTMs are essential regulators of protein function and they could be particularly important in organisms such as trypanosomatids where RNA pol II promoters are nearly absent. This study about putative polyglutamylases in trypanosomatids provides insights into an original PTM, polyglutamylation, which is extensively present in these parasites. Our data strongly suggest that LmTTLL4A and LmTTLL6B are bona fide MT polyglutamylases. The putative role of the other TTLLs is not understood. It is paradoxical, in view of the importance of tubulins in these organisms and their extensive glutamylation, that the inhibition of most TTLLs had no effect on cell growth or the cell cycle. This may suggest redundancy between polyglutamylases, as indicated here by the increased effect of the double TTLL4A + TTLL6B RNAi. Also, the role of polyglutamylation may be more subtle than can be shown here and/or limited in time: for example, as shown in several organisms, it may help to stabilise or, conversely, destabilise MTs; or it may produce varying signals for MAPs, MT-severing fac- 
tors or molecular motors (reviewed in Janke and Bulinski (2011)). Here, as in most cases, PTMs appear not to induce a loss/gain of function but rather a subtle modulation of this function, thereby likely playing a much larger and more complex role than presently suspected, yet difficult to grasp.

\section{Acknowledgments}

We gratefully acknowledge the essential technical assistance and expertise of Lucien Crobu in vector construction. We wish to thank Pierre Travo and the RIO Imaging Platform (Montpellier, France) for assistance in fluorescence microscopy. The monoclonal antibody 12G10 developed by J. Frankel and M. Nelson was obtained from the Developmental Studies Hybridoma Bank (IA, USA) developed under the auspices of the Eunice Kennedy Shriver National Institute of Child Health and Human Development (NICHD) and maintained by the University of Iowa, USA. This study was funded with the assistance of the Centre National de la Recherche Scientifique (CNRS) and the French Ministry of Higher Education and Research for PB's group and the Association pour la Recherche sur le Cancer (ARC) award $N^{\circ} 3140$, the French National Research Agency (ANR) awards Nos. 05-JCJC-0035 and 08-JCJC0007, and the Foundation pour la Recherche Medicale (FRM), France Research Grant DEQ20081213977 for CJ's group.

\section{Appendix A. Supplementary data}

Supplementary data associated with this article can be found, in the online version, at http://dx.doi.org/10.1016/j.ijpara.2014. 09.005.

\section{References}

Berriman, M., Ghedin, E., Hertz-Fowler, C., Blandin, G., Renauld, H., Bartholomeu, D.C., Lennard, N.J., Caler, E., Hamlin, N.E., Haas, B., et al., 2005. The genome of the African trypanosome Trypanosoma brucei. Science 309, 416-422.

Blaineau, C., Tessier, M., Dubessay, P., Tasse, L., Crobu, L., Pagès, M., Bastien, P., 2007. A novel microtubule-depolymerizing kinesin involved in length control of a eukaryotic flagellum. Curr. Biol. 17, 778-782.

Bobinnec, Y., Moudjou, M., Fouquet, J.P., Desbruyères, E., Eddé, B., Bornens, M., 1998 Glutamylation of centriole and cytoplasmic tubulin in proliferating nonneuronal cells. Cell Motil. Cytoskeleton 39, 223-232.

Bonnet, C., Boucher, D., Lazereg, S., Pedrotti, B., Islam, K., Denoulet, P., Larcher, J.C. 2001. Differential binding regulation of microtubule-associated proteins MAP1A, MAP1B, and MAP2 by tubulin polyglutamylation. J. Biol. Chem. 276, 12839-12848.

Boucher, D., Larcher, J.C., Gros, F., Denoulet, P., 1994. Polyglutamylation of tubulin as a progressive regulator of in vitro interactions between the microtubuleassociated protein Tau and tubulin. Biochemistry 33, 12471-12477.

Bré, M.H., de Néchaud, B., Wolff, A., Fleury, A., 1994. Glutamylated tubulin probed in ciliates with the monoclonal antibody GT335. Cell Motil. Cytoskeleton 27, 337 349.

Casanova, M., Crobu, L., Blaineau, C., Bourgeois, N., Bastien, P., Pagès, M., 2009. Microtubule-severing proteins are involved in flagellar length control and mitosis in trypanosomatids. Mol. Microbiol. 71, 1353-1370.

Dubessay, P., Ravel, C., Bastien, P., Crobu, L., Dedet, J.P., Pagès, M., Blaineau, C., 2002. The switch region on Leishmania major chromosome 1 is not required for mitotic stability or gene expression, but appears to be essential. Nucleic Acids Res. 30, 3692-3697.

Dubessay, P., Blaineau, C., Bastien, P., Pagès, M., 2004. Chromosome fragmentation in Leishmania. Methods Mol. Biol. 270, 353-378.

Dubessay, P., Blaineau, C., Bastien, P., Tasse, L., van Dijk, J., Crobu, L., Pagès, M., 2006. Cell cycle-dependent expression regulation by the proteasome pathway and characterization of the nuclear targeting signal of a Leishmania major Kin-13 kinesin. Mol. Microbiol. 59, 1162-1174.

Eddé, B., Rossier, J., Le Caer, J.P., Desbruyères, E., Gros, F., Denoulet, P., 1990. Posttranslational glutamylation of alpha-tubulin. Science 247, 83-85.

Gagnon, C., White, D., Cosson, J., Huitorel, P., Eddé, B., Desbruyères, E., PaturleLafanechère, L., Multigner, L., Job, D., Cibert, C., 1996. The polyglutamylated lateral chain of alpha-tubulin plays a key role in flagellar motility. J. Cell Sci. 109, 1545-1553.

Gull, K., 1999. The cytoskeleton of trypanosomatid parasites. Annu. Rev. Microbiol. 53, 629-655.

Hammarton, T.C., 2007. Cell cycle regulation in Trypanosoma brucei. Mol. Biochem. Parasitol. 153, 1-8.
Ikegami, K., Mukai, M., Tsuchida, J., Heier, R.L., Macgregor, G.R., Setou, M., 2006. TTLL7 is a mammalian beta-tubulin polyglutamylase required for growth of MAP2-positive neurites. J. Biol. Chem. 281, 30707-30716.

Janke, C., Rogowski, K., Wloga, D., Regnard, C., Kajava, A.V., Strub, J.M., Temurak, N., van Dijk, J., Boucher, D., van Dorsselaer, A., Suryavanshi, S., Gaertig, J., Eddé, B., 2005. Tubulin polyglutamylase enzymes are members of the TTL domain protein family. Science 308, 1758-1762.

Janke, C., Rogowski, K., van Dijk, J., 2008. Polyglutamylation: a fine-regulator of protein function? 'Protein Modifications: beyond the usual suspects' review series. EMBO Rep. 7, 636-641.

Janke, C., Kneussel, M., 2010. Tubulin post-translational modifications: encoding functions on the neuronal microtubule cytoskeleton. Trends Neurosci. 33, 362372

Janke, C., Bulinski, J.C., 2011. Post-translational regulation of the microtubule cytoskeleton: mechanisms and functions. Nat. Rev. Mol. Cell Biol. 12, 773-786.

Kohl, L., Gull, K., 1998. Molecular architecture of the trypanosome cytoskeleton. Mol. Biochem. Parasitol. 93, 1-9.

Kuryan, B.G., Kim, J., Tran, N.N., Lombardo, S.R., Venkatesh, S., Workman, J.L., Carey, M., 2012. Histone density is maintained during transcription mediated by the chromatin remodeler RSC and histone chaperone NAP1 in vitro. Proc. Natl. Acad. Sci. U.S.A. 109, 1931-1936.

Lacroix, B., van Dijk, J., Gold, N.D., Guizetti, J., Aldrian-Herrada, G., Rogowski, K., Gerlich, D.W., Janke, C., 2010. Tubulin polyglutamylation stimulates spastinmediated microtubule severing. J. Cell Biol. 189, 945-954.

Lacroix, B., Janke, C., 2011. Generation of differentially polyglutamylated microtubules. Methods Mol. Biol. 777, 57-69.

Larcher, J.C., Boucher, D., Lazereg, S., Gros, F., Denoulet, P., 1996. Interaction of kinesin motor domains with alpha- and beta-tubulin subunits at a tauindependent binding site. Regulation by polyglutamylation. J. Biol. Chem. 271, $22117-22124$.

Million, K., Larcher, J., Laoukili, J., Bourguignon, D., Marano, F., Tournier, F., 1999. Polyglutamylation and polyglycylation of alpha- and beta-tubulins during in vitro ciliated cell differentiation of human respiratory epithelial cells. J. Cell Sci. 112, 4357-4366

Moulay, L., Robert-Gero, M., Brown, S., Gendron, M.C., Tournier, F., 1996. Sinefungin and taxol effects on cell cycle and cytoskeleton of Leishmania donovani promastigotes. Exp. Cell Res. 226, 283-291.

Okada, M., Hozumi, Y., Ichimura, T., Tanaka, T., Hasegawa, H., Yamamoto, M., Takahashi, N., Iseki, K., Yagisawa, H., Shinkawa, T., Isobe, T., Goto, K., 2011. Interaction of nucleosome assembly proteins abolishes nuclear localization of DGK $\zeta$ by attenuating its association with importins. Exp. Cell Res. 317, 28532863.

Pathak, N., Obara, T., Mangos, S., Liu, Y., Drummond, I.A., 2007. The zebrafish fleer gene encodes an essential regulator of cilia tubulin polyglutamylation. Mol. Biol. Cell 18, 4353-4364.

Plessmann, U., Weber, K., 1997. Mammalian sperm tubulin: an exceptionally large number of variants based on several posttranslational modifications. J. Protein Chem. 16, 385-390.

Pradel, L.C., Bonhivers, M., Landrein, N., Robinson, D.R., 2006. NIMA-related kinase TbNRKC is involved in basal body separation in Trypanosoma brucei. J. Cell Sci. 119, 1852-1863.

Rastrojo, A., Carrasco-Ramiro, F., Martín, D., Crespillo, A., Reguera, R.M., Aguado, B., Requena, J.M., 2013. The transcriptome of Leishmania major in the axenic promastigote stage: transcript annotation and relative expression levels by RNA-seq. BMC Genomics 14, 223.

Redeker, V., Le Caer, J.P., Rossier, J., Promé, J.C., 1991. Structure of the polyglutamyl side chain posttranslationally added to alpha-tubulin. J. Biol. Chem. 266, $23461-23466$.

Regnard, C., Audebert, S., Desbruyères, E., Denoulet, P., Eddé, B., 1998. Tubulin polyglutamylase: partial purification and enzymatic properties. Biochemistry 37, 8395-8404.

Regnard, C., Desbruyères, E., Denoulet, P., Eddé, B., 1999. Tubulin polyglutamylase: isozymic variants and regulation during the cell cycle in HeLa cells. J. Cell Sci. 112, 4281-4289.

Regnard, C., Desbruyères, E., Huet, J.C., Beauvallet, C., Pernollet, J.C., Eddé, B., 2000. Polyglutamylation of nucleosome assembly proteins. J. Biol. Chem. 275, 1596915976.

Reilly, P.T., Afzal, S., Gorrini, C., Lui, K., Bukhman, Y.V. 2011. Acidic nuclear phosphoprotein 32kDa (ANP32)B-deficient mouse reveals a hierarchy of ANP32 importance in mammalian development. Proc. Natl. Acad. Sci. U.S.A. 108, $10243-10248$.

Robinson, D.R., Sherwin, T., Ploubidou, A., Byard, E.H0., Gull, K., 1995. Microtubule polarity and dynamics in the control of organelle positioning, segregation, and cytokinesis in the trypanosome cell cycle. J. Cell Biol. 128, 1163-1172.

Robinson, K.A., Beverley, S.M., 2003. Improvements in transfection efficiency and tests of RNA interference (RNAi) approaches in the protozoan parasite Leishmania. Mol. Biochem. Parasitol. 128, 217-228.

Rogowski, K., Juge, F., van Dijk, J., Wloga, D., Strub, J.M., Levilliers, N., Thomas, D., Bré, M.H., Van Dorsselaer, A., Gaertig, J., Janke, C., 2009. Evolutionary divergence of enzymatic mechanisms for posttranslational polyglycylation. Cell 137, 10761087.

Rüdiger, M., Plessman, U., Klöppel, K.D., Wehland, J., Weber, K., 1992. Class Il tubulin, the major brain beta tubulin isotype is polyglutamylated on glutamic acid residue 435. FEBS Lett. 308, 101-105.

Rüdiger, A., Rüdiger, M., Weber, K., Schomburg, D., 1995. Characterization of posttranslational modifications of brain tubulin by matrix-assisted laser desorption/ 
ionization mass spectrometry: direct one-step analysis of a limited subtilisin digest. Anal. Biochem. 224, 532-537.

Sasse, R., Gull, K., 1988. Tubulin post-translational modifications and the construction of microtubular organelles in Trypanosoma brucei. J. Cell Sci. 90, 577-589.

Seebeck, T., Hemphill, A., Lawson, D., 1990. The Cytoskeleton of trypanosomes. Parasitol. Today 6, 49-52.

Schneider, A., Plessmann, U., Weber, K., 1997. Subpellicular and flagellar microtubules of Trypanosoma brucei are extensively glutamylated. J. Cell Sci. $110,431-437$

Sherwin, T., Schneider, A., Sasse, R., Seebeck, T., Gull, K., 1987. Distinct localization and cell cycle dependence of $\mathrm{COOH}$ terminally tyrosinolated alpha-tubulin in the microtubules of Trypanosoma brucei brucei. J. Cell Biol. 104, 439-446.

Sherwin, T., Gull, K., 1989. Visualization of detyrosination along single microtubules reveals novel mechanisms of assembly during cytoskeletal duplication in trypanosomes. Cell 57, 211-221.

Shi, H., Djikeng, A., Mark, T., Wirtz, E., Tschudi, C., Ullu, E., 2000. Genetic interference in Trypanosoma brucei by heritable and inducible double-stranded RNA. RNA 6, 1069-1076.

Sterkers, Y., Lachaud, L., Crobu, L., Bastien, P., Pagès, M., 2011. FISH analysis reveals aneuploidy and continual generation of chromosomal mosaicism in Leishmania major. Cell. Microbiol. 2, 274-283.

van Dijk, J., Rogowski, K., Miro, J., Lacroix, B., Eddé, B., Janke, C., 2007. A targeted multienzyme mechanism for selective microtubule polyglutamylation. Mol. Cell 26, 437-448.

van Dijk, J., Miro, J Strub, JM., Lacroix, B, van Dorsselaer, A, Eddé, B, et al., 2008. Polyglutamylation is a post-translational modification with a broad range of substrates. J. Biol. Chem. 283, 3915-3922.

Verhey, K.J., Gaertig, J., 2007. The tubulin code. Cell Cycle 6, 2152-2160.

Vogel, P., Hansen, G., Fontenot, G., Read, R., 2010. Tubulin tyrosine ligase-like 1 deficiency results in chronic rhinosinusitis and abnormal development of spermatid flagella in mice. Vet. Pathol. 47, 703-712.
Weber, K., Schneider, A., Westermann, S., Müller, N., Plessmann, U., 1997. Posttranslational modifications of alpha- and beta-tubulin in Giardia lamblia, an ancient eukaryote. FEBS Lett. 419, 87-91.

Westermann, S., Weber, K.J., 2003. Post-translational modifications regulate microtubule function. Nat. Rev. Mol. Cell Biol. 4, 938-947.

Westermann, S., Schneider, A., Horn, E.K., Weber, K., 1999. Isolation of tubulin polyglutamylase from Crithidia; binding to microtubules and tubulin, and glutamylation of mammalian brain a- and b-tubulins. J. Cell Sci. 112, 2185 2193.

Wheeler, R.J., Gluenz, E., Gull, K., 2011. The cell cycle of Leishmania: morphogenetic events and their implications for parasite biology. Mol. Microbiol. 79, 647-662.

Wloga, D., Rogowski, K. Sharma, N., van Dijk, J., Janke, C., Eddé, B., Bré, M.H. Levilliers, N., Redeker, V., Duan, J., Gorovsky, M.A., Jerka-Dziadosz, M., Gaertig, J., 2008. Glutamylation on alpha-tubulin is not essential but affects the assembly and functions of a subset of microtubules in Tetrahymena thermophila. Eukaryot. Cell 8, 1362-1372.

Wloga, D., Webster, D.M., Rogowski, K., Bré, M.H., Levilliers, N., Jerka-Dziadosz, M. Janke, C., Dougan, S.T., Gaertig, J., 2009. TTLL3 is a tubulin glycine ligase that regulates the assembly of cilia. Dev. Cell 16, 867-876.

Wloga, D., Gaertig, J., 2010. Post-translational modifications of microtubules. J. Cell Sci. 123, 3447-3455.

Wolff, A., de Néchaud, B., Chillet, D., Mazarguil, H., Desbruyères, E., Audebert, S. Eddé, B., Gros, F., Denoulet, P., 1992. Distribution of glutamylated alpha and beta-tubulin in mouse tissues using a specific monoclonal antibody, GT335. Eur J. Cell Biol. 59, 425-432.

Wolff, A. Houdayer, M., Chillet, D, de Néchaud, B., Denoulet, P, 1994. Structure of the polyglutamyl chain of tubulin: occurrence of alpha and gamma linkages between glutamyl units revealed by monoreactive polyclonal antibodies. Biol Cell 81, 11-16. 